Horizontes. Revista de Investigación en Ciencias de la Educación

ISSN 2616-7964

enero-marzo, 2017

Volumen 1, Número 1

pp. $25-32$

www.revistahorizontes.org

\title{
La axiología como praxis pedagógica de la identidad nacional
}

\section{The axiology as a pedagogical practice of national identity}

\author{
Marcos Luis Serrano Rodríguez \\ serranorodriguez.marcos@gmail.com \\ Universidad Militar Bolivariana de Venezuela
}

Recibido: 15-07-2016 / Revisado: 20-07-2016 / Aceptado: 09-09-2016 / Publicado: 09-01-2017

RESUMEN

Este artículo tiene como propósito, desde la exégesis del autor, revelar la educación en valores como una adecuada praxis pedagógica de la identidad nacional. Trata de una propuesta inacabada y siempre abierta al debate sobre cómo debe ser el ejercicio de la función docente en su práctica, donde la identidad nacional será observada como objeto de estudio y la axiología como el instrumento para su propagación. En este sentido se considera necesario hacer un análisis holístico, realizado a través de una metódica hermenéutica como herramienta donde el investigador interactúa directamente con distintos causantes a través del análisis de fuentes primarias y secundarias, fundada en el suelo dialéctico como arte del entendimiento mutuo.

Palabras clave: Axiología, Identidad Nacional, Pedagogía, Praxis pedagógica, Hermenéutica
ABSTRACT

This article aims, from the author's exegesis, to reveal education in values as an adequate pedagogical praxis of national identity. It is an unfinished proposal and always opens to the debate on what should be the exercise of the teaching function in its practice, where the national identity will be observed as object of study and the axiology as the instrument for its propagation. In this sense, it is considered necessary to make a holistic analysis, carried out through a hermeneutical methodical as a tool where the researcher interacts directly with different causers through the analysis of primary and secondary sources, founded on the dialectical ground as art of mutual understanding.

Key words: Axiology, National Identity, Pedagogy, Pedagogical, Praxis, Mermeneutics 
Axiología como praxis pedagógica de la identidad nacional

Con la finalidad de facilitar la comprensión de la temática planteada, el investigador considera necesario realizar un estudio holístico del fenómeno de estudio teniendo como base la hermenéutica, para, de esta manera hilar de forma adecuada cada una de las concepciones que dan origen a su propuesta, donde primeramente se profundizara sobre la identidad nacional y sus elementos constitutivos para así apertura el espacio comprensivo donde la axiología será analizada como herramienta para la adecuada praxis pedagógica del objeto de estudio.

En este sentido es necesario comprender que la hermenéutica, según Hurtado (2010) es la disciplina mediadora que une la pluralidad de gramáticas con la universalidad de la crítica. Esta sistematización, permite determinar cómo se relacionan la individualidad del intérprete y la universalidad de la comprensión.

Para ello, la hermenéutica se acerca a la correcta interpretación del autor, con el fin de comprender lo expresado en el lenguaje de lo que quiso transmitir. Más que una técnica o conjunto de reglas para evitar los malentendidos, la hermenéutica es un saber próximo al arte del diálogo, porque son dos personas las que entran en contacto: el autor y el lector.

\section{De la identidad nacional}

Para autores como Rengifo (2006), hablar de identidad sugiere los aspectos trascendentes que definen los patrones culturales de cada sociedad y las diferencian de otras; expresadas a través de los sentimientos de pertenencia al grupo familiar donde se nace y se educa, comprendiendo al ámbito local, regional y nacional donde el individuo se ha desenvuelto.

Es claro que mencionados aspectos tienen que ver con la sociedad; se percibe como se va de lo individual en lo más interno del Ser, hasta llegar a lo colectivo, donde el ámbito nacional será la cúspide del sentimiento al cual se hace referencia. Se aprecia como de manera compleja el autor involucra elementos que merecen ser analizados de manera holística y que son pertinentes con la realidad que se vive y el objeto de estudio.

Ahora bien, hablar de identidad nacional, sin hacer referencia a las fuentes primarias sería un acto poco ético para el buen desarrollo de la temática planteada, en virtud de la comprensión que se logrará, al plasmar elementos de vieja data que en la actualidad tienen una vigencia bastante representativa y que por las características de su fundamento se hace necesario su estudio y comprensión, tal como lo expresara Serrano (2017).

En este sentido, es válido conocer que Herbert Spencer, filósofo y sociólogo inglés de finales del siglo XIX, estudió de manera profunda el comportamiento evolutivo de las sociedades, con la finalidad dar explicación a los fenómenos que suceden en ellas, tratando de usar como símil al ser humano visto como individuo; haciendo referencia a que las sociedades nacen, crecen, se desarrollan, envejecen y mueren al igual que el hombre. Visión criticada por muchos y apreciada por otros como instrumento idóneo para comprender el comportamiento general de las sociedades, donde se establece que la identificación tiene un doble sentido: desde el punto de vista individual y desde el social.

Desde el punto de vista individual se toma en consideración la relación existente entre los caracteres físicos y psíquicos que permiten al individuo sentirse igual a otros en lo que se entiende como el proceso de socialización y en el cual poco a poco el individuo se incorpora a un grupo, realizando dicho proceso desde la edad infantil hasta la adulta, donde al final se realiza un proceso más profundo de identificación que se divide en dos direcciones, por una parte hacia adentro, donde se toma conciencia de sí mismo en base a sus capacidades y limitaciones, y por otro lado hacia afuera, cuando el individuo aprecia el medio cultural que le rodea y la posición que ocupa, creando 
un vínculo o sentido de pertenencia hacia una sociedad o nación en particular a través de un nexo espiritual que será llamado identidad nacional.

Por lo tanto se entiende que la identidad nacional no involucra solo factores externos o tangibles que pueden ser percibidos de fácil manera, por el contrario, el término en su praxis debe emerger primero de lo más profundo del Ser y donde evolutivamente se ira adaptando desde adentro (individuo) hacia afuera (sociedad) en función de los sentimientos generados por la plena identificación de sí mismo en un espacio determinado que será común con sus similares, en lo que entenderemos entonces como el punto de vista social.

Por otra parte, Sequera (2004), señala que:

...la identidad de un país, de una región o de una etnia está siempre contenida en los elementos que constituyen su patrimonio cultural. En éste se reflejan los usos y las costumbres del grupo que lo conformó y por eso es importante su cuidado y mantenimiento.

Por ello, la identidad nacional involucra las costumbres que pasan de generación en generación y que muestran el modo de vida de un conjunto de personas agrupadas que van desde una etnia, por hablar de minorías, hasta llegar a una nación entera referenciando grupos considerablemente numerosos y que conviene su cuidado para que prevalezcan en el tiempo, ya que "...forman parte de esa memoria histórica que todos los venezolanos tienen en común. Una manera de que se mantengan es su difusión a través de la educación, medio idóneo para transmitir la cultura de los pueblos", según Romero (2011).

En este sentido es pertinente entender que la identidad Nacional es una fuerza intangible que ha permitido que muchos países se sobrepongan de las más grandes adversidades por muy difíciles que han sido, una fuerza que permite impeler masas $y$ transige a modificar el pensamiento del ser humano; un ejemplo muy claro de ello, según Fuentes (1995) fue "la fuerza de la identidad del japonés o del alemán, demostrada durante la Segunda Guerra Mundial y muy especialmente después de su derrota, donde muestran claramente la ubicación de conglomerados identificados con la idea nacional e imbuidos con un elevado espíritu de sacrificio".

Se comienza a comprender que la naturaleza de la Identidad Nacional está en el Ser y en la concepción de sí mismo como parte de una sociedad. Mientras tanto y en función de exponer sobre la temática otro de los factores propuestos, acertadamente Sequera (Ibid.) plantea la existencia de elementos que constituyen el patrimonio cultural de un individuo; en este sentido y realizando una investigación un poco más profunda, se puede apreciar que existen elementos que le dan fundamento a la Identidad Nacional.

Según Chalbaud (1998) son elementos constitutivos de la identidad nacional "el territorio, los símbolos patrios, el idioma, la educación moral y la identidad regional".

De acuerdo a estos elementos de Identidad Nacional que se pueden señalar, se hace notar la importancia que cada uno tiene en la identificación de una Nación; el hecho de conocer e internalizar el territorio, los símbolos, idioma y el regionalismo son características fehacientes de un alto espíritu nacionalista que serán elementos determinantes en la conformación del hombre nuevo.

En ese mismo orden de ideas, Fuentes (Ibid.) establece como elementos 0 componentes de identidad nacional: " $E l$ lenguaje, la historia, las costumbres, las tradiciones, los propósitos nacionales, la religión y los valores éticos".

Componentes que al igual que los anteriores reflejan el quehacer diario de una determinada sociedad, y que se caracteriza por señalar entre ellos la historia como parte de conocer los procesos por los cuales se 
pasaron para convertirse en nación, tomando en consideración las costumbres y tradiciones que sarán el toque personal de la caracterización de una sociedad. En otras palabras, del Ethos del Ser hacia la sociedad.

Por otra parte, Romero (Ob. cit.), insiste en que:

...la identidad nacional se va construyendo a través del sentimiento que crece cuando se empieza en la escuela, en todo ese trayecto, con el conocimiento sistemático y exhaustivo de los valores culturales, un sentimiento que a medida que aumenta impulsa a defender los valores $\mathrm{e}$ intereses patrios. (p. 45).

Es decir que al igual que expresa Spencer (1987), la identidad nacional se va desarrollando en procesos internos y externos del individuo que se van afianzando desde temprana edad a través del proceso de socialización al cual se enfrentará cuando se incorpora a un grupo, en el caso de Figueroa (2005) deja muy claro también, que dicho proceso de crecimiento de identidad nacional comienza en la escuela.

Lo interesante de la Identidad Nacional es que se comienza a percibir como algunos autores la definen como un valor y otros como un sentimiento, lo que se puede traducir en que, desde sus perspectivas, se le da una valoración más allá de cualquiera, por lo que se deduce que ciertamente la identidad nacional tiene una complejidad digna de estudio y análisis ya que en ella convergen varios elementos.

En este sentido Fuentes (Ob. cit.) indica que:

La identidad nacional es el vínculo espiritual que une a los hombres de una sociedad en base a una serie de características que hacen sentir a esos mismos hombres, que existe una comunidad entre ellos. Este nexo se debe convertir en todo caso en una actitud recíproca entre la colectividad y el hombre para que la identidad sea efectiva (p 55).
Es afirmativo el hecho que la Identidad Nacional, es un fenómeno de carácter social, que emerge de manera individual y tiene la valoración que cada individuo dentro de un colectivo le quiera dar, así como también existen dentro de ella unos elementos que la constituyen y que dan la base o los cimientos para su comprensión e interpretación, siguiendo las sugerencias planteadas por autores como Chalbaud (1998), Fuentes (1995) y Romero (2011), se realizara un sucinto análisis de algunos de ellos.

\section{Elementos constitutivos de la identidad Nacional}

Partiendo del acápite anterior y la exégesis de los autores presentados por el investigador, a continuación, se explicarán de manera muy sucinta algunos de los elementos que constituyen la identidad nacional.

\section{Territorio}

Es el espacio en el cual se vive y de donde se es; es decir, donde se desenvuelve cada uno de los grupos humanos, según lo expresado por Romero (Ob. cit.).

En este sentido, Chalbaud (Ob. cit.) indica que:

Más que hablar de territorio deberíamos referirnos y hablar de espacio geográfico para que el venezolano internalice que Venezuela es más que tierra, más que un espacio aéreo y que un subsuelo, a los cuales hay que defender, no sólo en su integridad y soberanía, sino en su calidad. (p 26).

De acuerdo a ello el investigador sugiere que la concepción del autor, debe ser entendida y asumida para cualquier país, teniendo presente la importancia de la identidad, el amor y el arraigo que debe existir para con el territorio, dado que en él nacen las riquezas que garantizan la vida de una nación. 


\section{Pasado Histórico}

Se debe entender que uno de los elementos que alienta la Identidad Nacional de cualquier país bolivariano, es su pasado histórico, forjado por el pueblo en sus luchas por la libertad y la justicia y por el pensamiento y la acción de los grandes servidores de la patria, cuya expresión más alta es el General en Jefe Simón Bolívar, El Libertador.

Para comprender la esencia del hombre en sociedad, se debe estar seguro de donde se viene, teniendo la capacidad de recordar su propio pasado, en lo que Fuentes (Ob. cit.) llama "la memoria de los pueblos", es por ello que la historia no puede ser despersonalizada, ya que es escrita, es conservada y recordada por los hombres, fortaleciendo así el lazo individuo-sociedad que debe existir al momento que se requiera defender los supremos intereses de la Patria.

\section{Símbolos Patrios}

Son expresiones que representan a la plétora de personas que hace vida en un país. En este sentido, Serfatty (2006), afirma que “... los símbolos patrios representan la autonomía y el carácter oficial de la nacionalidad".

Los símbolos patrios al igual que expresa el autor, son expresiones que identifican y realzan el carácter autónomo de cada nación, son las imágenes, colores e himnos que demuestran la manera más simbólica de cumplir con las tradiciones pasadas de generación en generación a lo largo de los años.

\section{Tradiciones}

Son todas aquellas expresiones que realiza el ser humano de manera individual o colectiva, que se trasmiten de generación en generación y que abarcan manifestaciones culturales 0 artísticas en todas sus expresiones; en este el investigador hará referencia a la música y la danza como expresiones del folklore donde la RENA (2004), afirma que este "es uno de los elementos más representativos de la identidad y del nacionalismo".

Además de éstas, también son parte de las tradiciones, las leyendas, los mitos y todo lo que constituye una parte de la llamada cultura informal, que recoge el sentir de los pueblos, concediéndole con ello una faceta fundamental de su propia identidad como lo expresara Fuentes (Ibid.). Por lo que se deduce que éste conglomerado forma parte de la identidad regional a la que hace referencia Chalbaud (Ob. cit.) donde "existen tradiciones, costumbres, músicas, modismos, artesanías y geografías diferentes...”

\section{Lenguaje}

En primera instancia, Fuentes (Ibid.) sostiene que los hombres requieren comunicarse entre sí, para establecer sus mutuos intereses y comportamientos. Entonces, en el lenguaje está presente la construcción ideológica, la manera de pensar y de actuar de una sociedad. Las personas de habla hispana han aceptado y usado a diario palabras extrajeras como por ejemplo okey, bye, shopping, entre otras, que de una u otra forma influyen en la desorientación de su lenguaje, logrando con esto restarle importancia al propio idioma.

Pero en sí, la gran importancia del lenguaje es que éste produce un efecto de identidad del hombre con sus semejantes en determinada sociedad, ya que por el simple hecho de expresarse de la misma manera lo hace sentir la existencia de un vínculo especial, según lo describe Fuentes (Ibidem.).

Una vez conocido el elemento fenomenológico de carácter social que implica tantos componentes que subyacen en él, se torna necesario el análisis del cómo divulgar e inculcar lo que, para algunos autores presentados, es un sentimiento y para otros un valor, teniendo presente que, como se 
quiera apreciar, es un elemento intangible, pero con una presencia significativa en cada región, lo que torna pertinente y justificado su estudio.

\section{En cuanto a la Axiología}

Desde el punto de vista etimológico, la palabra axiología proviene del griego axiavalor y logos- estudio; término de reciente origen, pues su introducción se produce a principios del siglo XX, según lo planteado por Fabelo (1989). Sin embargo, los antiguos griegos dedicaban parte del razonamiento filosófico a los llamados problemas de valor, tratándolos dentro de la llamada filosofía práctica; comenzando por constatar intuitivamente la existencia de valores, y después ocupándose del análisis filosófico, como casi siempre ocurría. Pero a raíz de que comenzaran a gestarse los primeros oficios y por ende la economía natural, se fomentaban valores exclusivistas que se concretizaban en el concepto de areté (virtud humana superior), integrada por el éxito material, la riqueza, felicidad, paz, moral y gloria; y que era propia de los aristoi o nobles y no de cualquier ciudadano, por lo que era tan hereditaria como la condición nobiliaria según lo describe Martínez (2010). Quien por otra parte afirma que la ética Nico Maquea de Aristóteles, es tal vez la obra axiológica de mayor importancia en los tiempos antiguos, ya que "no solo reflexiona acerca de la compleja esencia de la virtud, sino que también ofrece interesantes consejos y sugerencias para ayudar a la solución de los conflictos de valor".

A lo largo de los años, muchos autores trataron de dar respuesta a los conflictos de valor; muchas son las posturas presentadas en torno a este tema abstracto y holístico que conceptualizado y conjugado con lo filosófico se torna teleológico; sin embargo, el investigador realizó un análisis crítico y reflexivo de la postura de Immanuel Kant (1724-1804).
Sostiene Kanz (1993), que Immanuel Kant mantiene una postura basada en que la educación es absolutamente indispensable para el desarrollo de la humanidad, en virtud que el humano es un ser propenso a la libertad y acostumbrado a someterse a los dictados de la razón. El ser humano no es otra cosa de lo que la educación hace de él, señalando que éste se educa sólo por medio de otros seres humanos que también han sido educados a su vez; afirmando que la buena educación procede a todo bien en el mundo; para ello, el niño no debe ser formado en función del mejor estado del género humano presente, sino pensando en el mejor estado futuro.

Por esta razón presenta una postura crítica en su época, sobre el hecho que los padres educan a sus hijos sólo de forma que se adapten al mundo presente aún y cuando esté en descomposición, manteniendo su pensamiento sobre que una buena educación es apropiada para mejorar el mundo de manera paulatina, teniendo una continuidad con el pasar de las generaciones y de esta manera educar a futuro para la felicidad del ser humano, quien es el único responsable de su educación.

Como principales tareas de la educación, Kant señala cuatro: el disciplinamiento, el cultivamiento, la civilización y la moralización, admitiendo que para su época la educación se fundamentaba sólo en las tres primeras y agregando la moralización como el cimiento con el cual se transformaría la praxis pedagógica; debiendo ser desarrollada por los educadores hacia la deontología de las cosas.

La moralización se trata de aquellos procedimientos educativos que buscan desarrollar un carácter moral en los niños y jóvenes, ligada a la dignidad del ser humano, siendo interpretado en un sentido anticolonialista, antiimperialista y antibelicista o más bien cosmopolita; educando para que el ser cumpla con los 
deberes para consigo mismo y con los demás, tal como lo establece en sus escritos.

Con estas reflexiones de Kant, se puede inferir el génesis de la axiología como elemento fundamental para la educación moral o en valores; en ese sentido Gervilla (2000) sostiene que:

...todo acto educativo conlleva siempre una relación, explícita o implícita, al valor, por cuanto la educación en su misma esencia y fundamento es valiosa. De aquí que sea reiterativa la expresión "educar en valores", ya que no hay otra posibilidad de educar más que en valores. ( $p 39$ ).

Es decir que los valores hacen un orden de fundamentos, infiriendo que todo problema educativo, es entonces en el fondo, un problema axiológico, por lo que se hace esencial que la educación sea inseparable del valor para la formación de un ser integral, ya que, se le puede dar connotación subjetiva y objetiva para el desarrollo de un modelo donde se estimulan las potencias del educando basadas en la libertad, autonomía y creatividad.

Razón tenía el gran maestro Simón Rodríguez (2012) al aseverar que "es del cargo de maestro de la primera Escuela enseñar no sólo la formación de los caracteres sino su valor y propiedad". Es decir que la responsabilidad de efectuar una práctica docente donde se inculque no sólo el significado de las cosas o las cualidades que posee como parte de una estructura de forma, sino su valor como elemento intangible y que en realidad es lo que ayudara a comprender su valoración de fondo; es completamente competencia de quien educa, ya que sólo a través de una adecuada praxis pedagógica serán inculcados los elementos de valor de un Ser y a su vez de cualquier sociedad.

Es por ello que Rodríguez (Ibidem.) se torna insistente en dicha responsabilidad, ya que para el:

No es propiedad de lo que se aprende en la Escuela el olvidarse: lo será de lo que aprende mal; así como se desploma y arruina luego el edificio mal cimentado. Dígase que fue superficial la enseñanza y no que fue inútil. (p 40).

En efecto, una adecuada educación, no debe ser superficial, por el contrario, es la educación misma el cimiento para la formación del hombre de bien, de una persona en valores que será parte de la sociedad, y son esos valores aprendidos en la escuela y el hogar los que harán que el individuo tribute a su sociedad, para ello la Identidad Nacional juega un papel fundamental, ya que el ser humano por naturaleza desarrollará ese sentimiento de identificación primeramente consigo mismo y el entorno que lo rodee, para luego sentirse identificado con el colectivo que tiene en común algunos elementos constitutivos con los que se identifican las sociedades, regiones y naciones.

Lo dijo el Libertador ";hombres virtuosos, hombres patriotas, hombres ilustrados constituyen las repúblicas!".

\section{A manera de epílogo}

Se dio un breve pasar por la concepción de distintos causantes que discurren en la temática planteada como eje principal de este artículo, donde, a pesar de mostrarse aseveraciones distintas, a través de un ejercicio dialéctico, el investigador se permite, desde su exégesis, comprender que la Identidad Nacional es un elemento que se encuentra subyacente en el Ser y por ende en la sociedad, con elementos que la constituyen y la fortalecen como valor o sentimiento esencial, según la valoración que cada individuo le proporcione.

De aquí la preocupación del investigador en buscar una herramienta que permita la propagación correcta de dicho elemento ontológico, permitiéndose revelar, luego de una praxis dialéctica, la axiología como instrumento adecuado para tal fin, teniendo presente que todos los elementos intangibles que forman parte del Ser y que constituyen su esencia como persona de bien, deben ser inculcados con alto compromiso ético, para de esta manera enseñar al individuo la 
deontología que no es más que el deber ser de las cosas; y de esta manera coadyuvar a la educación adecuada de toda sociedad.

Más allá de enseñar las concepciones establecidas en distintas literaturas, el maestro debe enseñar la relevancia que presenta cada concepto y el valor que la sociedad le asigna como ejercicio ético. La Identidad Nacional es un tema complejo que no solamente debe ser comprendido en la escuela por así llamar a cualquier instituto educativo en cualquiera de sus niveles, por el contrario, al ser un tema que las sociedades le

\section{REFERENCIAS}

Chalbaud, D. (1998). Fronteras e identidad nacional venezolana y seguridad y defensa, Temas del IAEDEN No 12. Caracas, Venezuela.

Diccionario de la Real Academia Española. (2016). [Versión digital]. Edición del tricentenario. Disponible: www.rae.es.

Fabelo, J. (1989). Práctica, conocimiento y valoración. La Habana, Cuba: Editorial de Ciencias Sociales.

Figueroa, D. (2005). Soberanía e identidad nacional. Trabajo no publicado, Ciudad Guayana, Venezuela: Universidad de Oriente,

Fuentes, E. (1995). La Identidad Nacional Venezolana. Caracas, Venezuela: FUNDAIAEDEN.

Gervilla, E. (2000). Un modelo axiológico de educación integral. Revista española de pedagogía, no 215, pp. 39-58. Granada, España: Universidad de Granada.

Hurtado de B, J. (2010). Guía para la comprensión holística de la ciencia. Universidad Nacional Abierta. Venezuela, Caracas: Fundación Sypal.

Kanz, H. (1993). Immanuel Kant. Perspectivas: Revista trimestral de Educación Comparada. UNESCO: Oficina Internacional de Educación. [Revista en línea] Disponible: han dado una alta valoración por constituir un eje medular de las misma, se requiere que cada individuo, cada ciudadano, maestro, padre, amigo, en fin, que todos y cada uno de los que conforman una sociedad, se conviertan en multiplicadores de este elemento abstracto que ha permitido a lo largo del Cronos, que las personas se sientan identificadas con sus semejantes y con el territorio que habitan, como factor fundamental para la conformación de una sociedad auto determinada.

http://www.ibe.unesco.org/sites/default/f iles/kants.pdf [Consulta: 2017, junio 30].

Martínez, J. (2010). En torno a la axiología y los valores. Contribuciones a las Ciencias Sociales. Universidad José Martí Pérez. Cuba [Revista en línea]. Disponible: http://www.eumed.net/libros/404.html [Consulta: 2017, marzo 11].

RENa (Red Escolar Nacional, 2005). La identidad nacional Cuarta etapa educación premilitar. Disponible: www.rena.edu.ve [Consulta: 2017, junio 09].

Rengifo, D. (2006). Historia, educadores e identidad nacional. Trujillo: AGORA. Venezuela.

Rodríguez, S. (2012). Inventamos o erramos. Caracas, Venezuela: Fundación imprenta de la cultura.

Romero, N. (2011). National identity in the Venezuelan University Education. Revista Científica Electrónica de Ciencias Humanas [Revista en línea], 19(7), 56-71. Disponible:

http//www.revistaorbis.org.ve [Consulta: 2017, abril 10].

Sequera, J. (2004). Cultura y patrimonio. Consejo Nacional de la Cultura. Caracas, Venezuela. 